\title{
IMPLEMENTASI NILAI-NILAI FILOSOFIS JOGED MATARAM KE DALAM SISTEM PEMBELAJARAN TARI SLTP KOTA YOGYAKARTA
}

\section{Kuswarsantyo}

\section{FBS Universitas Negeri Yogyakarta}

\section{Abstrak}

Various studies on the philosophical values of Joged Mataram have been conducted. However, in the context of dance learning, a study that relates the values and the dance learning system has never been carried out Therefore, the writer is interested to analyze the problem through a descriptive qualitive research. The result and the effectivens of the application of Joged Matitative philos to the dance learning system can be used as aned Mataram philosophy to the dance learning system can be used as an achievement measurement, with dance teachers as the main informants. Four aspects of Joged Mataram philosophy are Sawiji, the realization of always concentrating on facing all activities; Greged, the expression of human life dynamic; Sengguh, human self-evidence in all situations without being arrogant; and Ora Mingkuh, an attitude of always struggling to realize a dream. Understanding the aspects, students are hopefully able to follow the dance learning process with all their heart to reach their ideals.

Key Words: values, Joged Mataram, dance learning

\section{A. Pendahuluan}

\section{Latar Belakang}

Ketidaktertarikan siswa pada mata pelajaran kesenian saat ini karena kesenian dianggap tidak prospektif dalam mendukung potensi pengembangan intelegensi siswa. Hal ini diperkuat dukungan serta pandangan orangtua siswa terhadap mata pelajaran kesenian yang selalu dianggap praktik oriented (skill)

Kenyataan sebenarnya, kesenian tidak hanya terbatas pada pengembangan aspek keterampilan, tetapi menyangkut substansi yang lebih luas pada perilaku yaitu masalah afektif maupun keilmuan atau kognitifnya.

Melihat fungsinya sebenarnya pendidikan seni memiliki fungsi dan tujuan sebagai media untuk mengembangkan sikap dan kemampuan agar siswa mampu berkreasi dan peka dalam berkesenian (Depdiknas, 2001:7) Bahkan secara rasional pelajaran pendidikan seni di sekolah didasarkan pada hal-hal sebagai berikut :

a. Pendidikan seni memiliki sifat multilingual, multidimensional dan multikultural

b. Pendidikan seni memiliki peranan dalam pembentukan pribadi siswa yang harmonis dalam logika, rasa estetis dan artistiknya serta etikanya dengan memperhatikan kebutuhan dan perkembangan anak untuk mencapai kecerdasan (EQ), kecerdasan intelektual (IQ), kecerdasan adversitas (AQ) dan kreativitas (CQ) serta kecerdasan spiritual dan moral. 
Sasminta Mardawa, Surya Kencana, dan Irama Citra.

Sejak tahun 1990-an pertunjukan untuk wisatawan di keraton Yogyakarta diselenggarakan setiap hari Minggu pukul 11.00 WIB, selama satu setengah jam pertunjukan diawali oleh tari tunggal putri atau putra, tari berpasangan, dan diakhiri oleh sendratari Ramayana atau Mahabarata. Beberapa tarian yang biasanya dipentaskan adalah tari Golek, Srimpi, Klana Topeng Gagah atau Klana Topeng Alus. Tari berpasangan yang menggambarkan dua tokoh dengan tema peperangan seperti Srikandi versus Suradewati, Srikandi versus Bisma Sudarawerti versus Sirtupelaeli, Rengganis versus Widaninggar, Anoman versus Yaksadewa, Gatutkaca versus Suteja, Umarmaya versus Umarmadi, dan sebagainya.

3. Peran Pimpinan dalam Organisasi Tari

K.R.T Sasmintadipura sebagai ketua organisasi tari Mardawa Budaya dan YPBSM sejak 1962-1996 memegang peranan yang sangat penting dalam mempertahankan dan mengembangkan organisasi tari gaya Yogyakarta. Namun demikian Rama Sas panggilan akrab K.R.T. Sasmintadipura tetap berorientasi pada perkembangan jaman, artinya segala sesuatu harus mampu memenuh kebutuhan meski misi utamanya pelestarian (Joan Suyenaga, 1999: 30). Dalam konteks ini ia telah mengembangkan materi pelajaran tari yang memenuhi norma tradisi klasik yang menjadi lebih mudah dipelajari oleh siswa-siswinya sesuai dengan generasi jaman ini. Lembaga pendidikan formal pada tingkat sekolah dasar, menengah maupun perguruan tinggi menggunakan materi tari yang diperoleh di organisasi tari sebagai materi pelajaran seni tari.

Pimpinan YPBSM pada periode kepengurusan 2005-2008 Siti Sutiyah Sasmintadipura mempunyai tanggung jawab meneruskan cita-cita Rama Sas, aga kegiatan kesenian dapat berjalan terus. Untuk itu organissi tari YPBSM dengan tangan terbuka mengharapkan bantuan dari berbagai pihak untuk bekerjasama sebagai mitra usaha pertunjukan wisata terutama bidang manajemen pertunjukan Begitu pula penuturan R.M. Dinu Satama selaku pimpinan Yayasan Siswa Among Beksa bahwa seorang pimpinan sebuah organisasi tari mempunyai peranan sangat penting yang bertanggung jawab pada kelangsungan hidup organisasi, secara profesional menghimpun dana dan mempunyai loyalitas di masyarakat.

Tujuan untuk melestarikan bagi Rama Sas adalah diawali dari rasa handarbeni atau merasa memiliki, dengan kecintaan penuh maka akan timbul nia supaya tari klasik gaya Yogyakarta ini langgeng hidup sepanjang masa. Dijelaskan pula oleh Siti Sutiyah Sasmintadipura bahwa bagaimanapun kondisi YPBSM, ia akan berusaha meneruskan cita-cita Rama Sas untuk selalu melestarikan dan mengembangkan tari klasik gaya Yogyakarta.

Kegiatan yang telah diselenggarakan oleh dua organisasi tari itu untuk mencapai tujuan melestarikan dan mengembangkan tari klasik gaya Yogyakarta baik pengembangkan dalam arti menciptakan bentuk-bentuk baru maupun menggunakan multi media, yaitu media audio, visual, dan audio visual sangat menarik, menyenangkan dan memudahkan mahasiswa dalam memahami dan mempraktekkan materi pelajaran. Dengan multimedia terpadu tersebut pembalajaran menjadi sangat efisien dan efektif.

Pengaruh penggunaan multimedia terpadu terhadap prestasi belajar direksi diteliti dengan cara membandingkan antara prestasi belajar direksi sebelum pembelajaran dan sesudah pembelajaran. Berdasarkan uji t yang dilakukan terhadap sekor pre-tes dan formatif tes pada siklus I, siklus II, dan siklus III, menunjukkan bahwa prestasi belajar antara pre-tes dan formatif tes berbeda secara signifikan pada signifikansi 5\%. Nilai rata-rata formatif tes siklus I,siklus II, dan siklus III lebih tinggi dari pada pre-tes. Perbedaan sekor rata-rata tersebut dianalisa dengan uji-Dunnet, ternyata signifikan pada taraf signifikansi $5 \%$, dengan demikian dapat dikatakan bahwa multimedia terpadu dapat meningkatkan prestasi belajar direksi.

D. Penutup

1. Simpulan berikut:

Berdasarkan analisa hasil penelitian diperoleh kesimpulan sebagai

a. Penggunaan Multimedia Terpadu pada pembelajaran direksi menjadikan pembelajaran menjadi menyenangkan, menarik perhatian, dan memudahkan mahasiswa dalam memahami dan mendemonstrasikan pola aba-aba.

b. Penggunaan Multimedia Terpadu dapat meningkatkan prestasi belajar mahasiswa, karena terbukti perbedaan antara sebelum dan sesudah pembelajaran signifikan.

2. Saran

a. Pada pembelajaran direksi sebaiknya menggunaan multimedia terpadu agar pembelajaran berjalan secara efektif dan efisien.

b. Penggunaan multimedia terpadu harus digunakan sesuai dengan kebutuhan dan tepat waktu.

c. Perlu dilakukan penelitian sejenis pada mata kuliah-mata kuliah prakteik musik yang lain.

\section{DAFTAR PUSTAKA}

Atmodjo, Subronto Kusumo. (n.d). Penuntun Pukulan Birama. Yogkarta : PLM Angwin Jenifer. 1997. The First Intrnational Handbook of Action research for Indonesian educators. Yogyakarta : IKIP Yogyakarta

Degeng, I. Nyoman S. 2001. Media Pembelajaran- Menuju Pribadi Unggul. Malang : Universitas Negeri Malang.

DePorter, Bobbi \& Hernacki, Mike. 2001. Quantum Learning. Membiasakan Belajar Nyaman dan Menyenangkan. Jakarta : Mizan. 
lembaga pendidikan formal. Bisa dikatakan jumlah yang tak terhitung lagi guruguru tari yang tersebar di seluruh Indonesia bahkan sampai ke luar negeri.

Di era global ini organisasi tari mampu bertahan menyelenggarakan kegiatannya, seperti yang telah dilakukan Yayasan Siswa Among Beksa dan Yayasan Pamulangan Beksa Sasmintadipura beserta pendukungnya, memberikan secercah harapan bahwa tari klasik gaya Yogyakarta tidak akan punah. Anakanak, remaja, dan dewasa baik dari kalangan pelajar maupun masyarakat umum berminat mengikuti pendidikan pada kedua organisasi tari tersebut ini.

Pelaku seni baik sebagai seniman, guru, pengelola organisasi tari, maupun pelaku birokrasi di pemerintahan selayaknya mempunyai rasa tanggung jawab bersama dan kompak dalam menghadapi tantangan kelangsungan hidup tari klasik gaya Yogyakarta. Pengelola organisasi tari hendaknya mempunyai kemampuan manajemen secara profesional. Walaupun mengelola seni pertunjukan tradisional, namun perlu menerapkan manajemen secara profesional agar organisasi mampu hidup dan berkembang sepanjang zaman sesuai dengan perubahan masyarakatnya.

\section{DAFTAR PUSTAKA}

Endraswara, Suwardi. 2004. Budi Pekerti Jawa Tuntunan Luhur dar Budaya Adiluhung. Yogyakarta: Gadjah Mada University Press.

Suyenaga, Joan. 1999. Rama Sas, Pribadi, Idealisme, dan Tekadnya. Bandung: Masyarakat Seni Pertunjukan.

Kayam, Umar. 1981. Seni Tradisi Masyarakat. Jakarta: Sinar Harapan. Koentjaraningrat. 1987. Sejarah Teori Antropologi I. Jakarta: Universitas Indonesia Press.

Koentjaraningrat. 1984. Kebudayaan Jawa. Jakarta: PN. Balau Pustaka,

Lindsay, Jennifer. 1990. Klasik, Kitsch, Kontemporer: Sebuah Studi Tentang Seni Pertunjukan Jawa.Terj. Nin Bakdi Sumanto. Yogyakarta: Gadjah Mada University Press.

1999. Seni Pertunjukan Dan Pariwisata. Bandung: Masyarakat Seni

Pertunjukan. Soedarsono, R.M.. 2002 Seni Pertunjukan Indonesia Di Era

Globalisasi. Yogyakarta: Gadjah Mada University Pressj.

Soedarsono, R.M. 2003. Seni Pertunjukan dari Perspektif Politik, Sosial, dan Ekonomi. Yogyakarta: Gadjah Mada University Press,.

Soedarsono, R.M. 2006. "Kearifan Lokal Dalam Seni Pertunjukan Tradisional" Makalah Seminar Festival Seni Pertunjukan Internasional, PPPG Kesenian Yogyakarta, 13 Nopember 2006

Soemaryatmi. 1998. "Kehadiran Tari gaya Surakarta di Daerah Istimewa Yogayakarta”. Tesis. Program Pascasarjana Universitas Gadjah Mada,

Sumardjan, Selo. 1981. "Kesenian dalam Perubahan Kebudayaan” dalam Analisis Kebudayaan”. Jakarta: Pendidikan dan Kebudayaan. 